\title{
Kaempferol separated from Camellia oleifera meal by high-speed countercurrent chromatography for antibacterial application
}

\author{
Yuanxin Qiu ${ }^{1} \cdot \mathrm{Di} \mathrm{He}^{1} \cdot$ Jingxian Yang ${ }^{1} \cdot$ Lukai Ma $^{1} \cdot \mathrm{Kaiqi}^{\mathrm{Zh}}{ }^{1} \cdot$ Yong Cao $^{2}$
}

Received: 12 May 2020 / Revised: 24 July 2020 / Accepted: 25 July 2020 / Published online: 9 August 2020

(c) Springer-Verlag GmbH Germany, part of Springer Nature 2020

\begin{abstract}
Natural biologically active substances have received continuous attention for the potentially beneficial health properties against chronic diseases. In this study, bacteriostatic active substance from Camellia oleifera meal, which is a major byproduct of the Camellia oil processing industry, were extracted with continuous phase change extraction (CPCE) method and separated by HSCCC. Compared with traditional extraction methods, CPCE possessed higher extraction efficiency. Two main substances were separated and purified (above 90.0\%). The structure of them were further identified by UV, LC-ESI-MS-MS, $1 \mathrm{H}-\mathrm{NMR}$, and $13 \mathrm{C}-\mathrm{NMR}$ as flavonoids F2 kaempferol 3- $O$-[ $\beta$-D-glucopyranosyl- $(1 \rightarrow 2)-\alpha$-L-rhamnopyranosyl- $(1 \rightarrow 6)]-\beta$-Dglucopyranoside and J2 kaempferol 3- $O$-[ $[\beta$-D-xylopyranosyl- $(1 \rightarrow 2)-\alpha$-L-rhamnopyranosyl-( $1 \rightarrow 6)]-\beta$-D-glucopyranoside for the first time in $C$. Oleifera meal. The results of antibacterial activity measurement showed that both compounds have excellent antibacterial activity. And the antibacterial stability of F2 were finally confirmed: F2 showed broad spectrum antibacterial activity against Escherichia coli, Staphylococcus aureus, Salmonella enteriditis, Bacillus thuringiensis, Aspergillus niger and Rhizopus nigricans. Besides, F2 exhibited relatively high stable property even at high temperature, acid and metal ion solutions. The findings of this work suggest the possibility of employing $C$. oleifera meal as an attractive source of health-promoting compounds, and at the same time facilitate its high-value reuse and reduction of environmental burden.
\end{abstract}

Keywords Antibacterial activity $\cdot$ Camellia oleifera meal $\cdot$ High-speed countercurrent chromatography $\cdot$ Kaempferol

Yong Cao

Yong13779830690@163.com

Yuanxin Qiu

65518987@qq.com

Di He

2860602862@qq.com

Jingxian Yang

1084061293@qq.com

Lukai Ma

m1991lk@163.com

Kaiqi Zhu

840105434@qq.com

1 School of Light Industry and Food, Zhongkai University of Agricultural and Engineering, Guangzhou 510220, China

2 School of Food Science and Engineering, South China Agricultural University, No. 483 Wushan Road, Wushan Street, Tianhe District, Guangzhou 510000, China

\section{Introduction}

Camellia oleifera, has about 280 species worldwide, and was as an important source of edible oil for 1000 years. It is mainly used to produce camellia oil, which exhibits very similar fatty acid profiles $[1,2]$ and provides a variety of health benefits, such as prevention of cardiovascular and gastrointestinal diseases [3]. However, with the increasing consumption and production of camellia oils, high contents of insoluble waste by-products also raise rapidly. The amount could be about 162 million tons per-year [4]. Thus, to develop comprehensive utilization of $C$. oleifera meal has become a hotspot worldwide.

Except for the utilization of detergent [5], Recently, $C$. oleifera meal has been attractive as a raw material for extracting biologically active compounds including saponins, flavonoids and polysaccharides etc. [6, 7]. Saponins obtained from the $C$. oleifera meal were an important natural product with antioxidant and anti-inflammatory properties [8]. In addition, triterpenoid saponins extracted from tea oil seed meal had been identified as important plant secondary metabolites and 
possessed a variety of pharmacological and biological activities [9], Besides, a broad spectrum of antiproliferative effects of triterpenoid saponins at the micromolar levels of human lung, stomach, breast, liver and colon tumor cell lines [10, 11], a promising strategy for disease [12]. Moreover, studies have shown that saponins also have anti-allergy, anti-hyperlipidemia [13] and anti-viral activity [14]. There are many tea saponins in $C$. oleifera meal to be studied. Flavonoids in $C$. oleifera meal have many desirable health benefits, like antiinflammatory, antiviral and antioxidative [15], which may help to prevent various chronic diseases including cardiovascular and obesity diseases $[16,17]$. In addition, various methods for extracting phytochemicals from agricultural food waste have been developed, and many biologically active substances have been identified and purified from C. oleifera meal $[18,19]$. However, relatively less research on bacteriostatic; Meanwhile, the extraction and purification efficiency of antibacterial active substance is still very low, and the method of extracting active bacteriostatic substance from $C$. oleifera meal has yet to be explored. To further improve the utilization of $C$. oleifera meal, it is necessary to develop effective method for improving extraction and purification efficiency of antibacterial substances, and to investigate the chemical structure of antibacterial compounds.

In addition, after the extraction of biocompounds, the separation of biocompounds is necessary to carry out. Generally, a conventional method for separating bacteriostatic active substance from crude extracts, for example, column chromatography on Sephadex LH-20, has a low yield and a high risk of sample denaturation [20]. In case of HSCCC, it has the advantages of high efficiency and high sample recovery rate and has been widely used to separate various natural phytochemicals $[21,22]$. Furthermore, to date, there have been no reports on the application of CPCE in combination with HSCCC for the extraction and isolation of active substance.

In this study, biocompounds was extracted from C. oleifera meal by CPCE method, and its effect and efficiency are very satisfactory. And then, biocompounds were separated by HSCCC. Finally, these biocompounds were researched for antibacterial application. And two biocompounds (defined as F2 and J2) exhibited excellent antibacterial activity. In order to investigate the chemical structure of two biocompounds, they were identified by LC-MS [23], 1H-NMR, and 13C-NMR [24]. Moreover, to further confirm the antibacterial activity of $\mathrm{F} 2$, more antibacterial experiments were carried out.

\section{Materials and methods}

\section{Experiment materials}

The $C$. oleifera meal was provided by Guangdong Ruifeng Agricultural Co., Ltd. (Guangdong, China).
Test strains: All the strains used in the study were provided by Guangdong Institute of Microbiology and saved by Microbiology Laboratory, College of Food Science, South China Agricultural University (Guangdong, China).

\section{Chemicals and instruments}

For extract preparation and HSCCC separation, all organic solvents were of analytical grade. HPLC-grade methanol was purchased from Thermo Fisher Scientific (China) Co., Ltd. (Shanghai, China).

Kanamycin for determination of bacteriostatic experiment was obtained from Beijing Pubo Biological Co., Ltd. (Beijing, China).

The CPCE was the self-designed patented product of the research group of the natural product chemistry laboratory of the Food College of South China Agricultural University. The CPCE method was used to extract the active ingredients in C. oleifera meal. The dried and crushed C. oleifera meal raw material was first loaded into the extraction kettle of a continuous phase change extraction device, which was always below the critical pressure and critical temperature of the extractant. Under conditions, the high-pressure pump compresses the extractant into a liquid, flowed through the extraction kettle at a certain flow rate to extract the camellia oil, and entered the decomposing kettle, where the extractant phase was turned into a gas by heating and depressurizing, and then cooling by instant cooling, the extractant became liquid and returned to the solvent recovery tank. The liquid extractant in the tank flows through the extraction kettle again through the pressure pump to extract the material again, and the cycle was repeated many times. The HSCCC was performed using a TBE-300A HSCCC instrument consisting of three Teflon preparation coils and a manual sample loop. The solvent was pumped into the column and the UV absorbance was monitored by the LC-10 ATVP system. The HPLC analyses were conducted using an Agilent OSD- $\mathrm{C}_{18}$ column $(250 \mathrm{~mm} \times 4.6 \mathrm{~mm}, 5 \mu \mathrm{m})$. The chemical structure was identified by LC-MS, ${ }^{1} \mathrm{H}-\mathrm{NMR}$ and

${ }^{13}$ C-NMR [25] (AVANCE-400/500, Swiss Bruker); fluorescence microscope (DM5000B, Olympus, Japan); UV-visible spectrometer (UV3010, Hitachi, Japan).

\section{Extraction of bacteriostatic substance}

\section{Single factor test of CPCE}

The dried powder of $C$. oleifera meal $(1.5 \mathrm{~kg})$ was extracted with $50 \%, 60 \%, 70 \%, 80 \%$, or $90 \%$ ethanol at $80{ }^{\circ} \mathrm{C}$ and 0.4 MPa for $2 \mathrm{~h}$.; The dried powder of $C$. oleifera meal $(1.5 \mathrm{~kg})$ was extracted with $80 \%$ ethanol at $80{ }^{\circ} \mathrm{C}$ and $0.3 \mathrm{MPa}, 0.4 \mathrm{MPa}, 0.5 \mathrm{MPa}, 0.6 \mathrm{MPa}$ or $0.7 \mathrm{MPa}$ for $2 \mathrm{~h}$.; The dried powder of $C$. oleifera meal $(1.5 \mathrm{~kg}$ ) was extracted 
with $80 \%$ ethanol at $50{ }^{\circ} \mathrm{C}, 60{ }^{\circ} \mathrm{C}, 70{ }^{\circ} \mathrm{C}, 80{ }^{\circ} \mathrm{C}$ or $90{ }^{\circ} \mathrm{C}$ and $0.4 \mathrm{MPa}$ for $2 \mathrm{~h}$.; The dried powder of C. oleifera meal $(1.5 \mathrm{~kg})$ was extracted with $80 \%$ ethanol at $80{ }^{\circ} \mathrm{C}$ and $0.4 \mathrm{MPa}$ for $1 \mathrm{~h}, 2 \mathrm{~h}, 3 \mathrm{~h}, 4 \mathrm{~h}$ or $5 \mathrm{~h}$. All above ethanol extract were respectively concentrated under reduced pressure and freeze-dried, for bacteriostatic experiment of Escherichia coli (E. coli), Staphylococcus aureus (S. aureus) and Aspergillus niger (A. niger).

\section{Orthogonal test of CPCE}

According to the optimal experimental conditions obtained by single factor experiment, the $\mathrm{L}_{9}\left(3^{4}\right)$ orthogonal test was designed. As shown in Table 1, the contents of the extracts under different factors such as ethanol concentration, extraction time, extraction temperature and extraction pressure were studied, according to range analysis, the optimum extraction conditions were obtained.

\section{Preliminary separation of strong antibacterial active components from crude extracts of $C$. oleifera meal}

The C. oleifera meal was extracted with $80 \%$ ethanol at $60{ }^{\circ} \mathrm{C}$ and $0.4 \mathrm{Mpa}$ for $4 \mathrm{~h}$, and Concentrated and dried, then taken moderate amount of them and dissolved by appropriate amount of distilled water to getting a cloudy aqueous suspension, and shaken well, and transferred to a separating funnel, then add petroleum ether, and full shaken extraction, let it Stand still, after the solution was completely layered, the upper petroleum ether extract was discharged and the extraction was carried out in small amounts until the petroleum ether layer was clear and colorless. The extracts were combined and concentrated under reduced pressure to get petroleum ether extract (SYM); the sample remaining after extraction with petroleum ether was dissolved in an appropriate amount of distilled water, and ethyl acetate was added thereto, and the mixture was shaken thoroughly, let it Stand still, after the solution was completely layered, the upper ethyl acetate extract was discharged, and the extraction was carried out in small portions until the ethyl acetate layer was clear and colorless. The extracts were combined and concentrated under reduced pressure to get ethyl acetate extract (YSYZ); the sample remaining after extraction with ethyl acetate was dissolved in an appropriate amount of distilled water, $n$-butanol was added, and the mixture was shaken thoroughly, and allowed to stand. After the solution was completely layered, the upper $n$-butanol extract was discharged, and a small amount of extraction was used until the $n$-butanol layer was clear and colorless. The extracts were combined and concentrated under reduced pressure to get $n$-butanol extract (ZDC); the sample remaining after extraction with the above three organic solvents was concentrated under reduced pressure to get a water component, which was designated as SZF.

The bacteriostatic activity of the above four components was tested separately. Thereby determining the best extraction solvent for the bacteriostatic substance.

\section{Antibacterial activity detection method}

\section{Bacteriostatic inhibition experiment}

Configuration of the medium (LB solid medium preparation method): the tryptone, yeast powder, sodium chloride and agar were respectively weighed $10.0 \mathrm{~g}, 5.0 \mathrm{~g}, 10.0 \mathrm{~g}$, and $20 \mathrm{~g}$, heated and stirred in $1000 \mathrm{ml}$ of water, packing, high pressure moist heat sterilization at $121{ }^{\circ} \mathrm{C}$ for $20 \mathrm{~min}$, and spared.

Activation of strains: Put the medium into the high temperature sterilizer at $121{ }^{\circ} \mathrm{C}$ for $20 \mathrm{~min}$, and cooled down, use the inoculating loop to pick a single colony from the strain plate in 3-5 $\mathrm{ml}$ of LB liquid medium. Cultured by a constant temperature shaker at $37{ }^{\circ} \mathrm{C}$ and $250 \mathrm{r} / \mathrm{min}$ for a night.

Preparation of bacterial suspension: Then take more than $30 \mu \mathrm{l}$ of the bacterial suspension and transfer it to $3 \mathrm{ml}$ of fresh LB liquid medium for reactivation. Cultured in the constant temperature shaker at $37{ }^{\circ} \mathrm{C}$ and $250 \mathrm{r} / \mathrm{min}$ for 3-5 $\mathrm{h}$, measure the OD value, dilute with LB liquid medium to $\mathrm{OD}_{600}=0.01-0.1$ (i.e., the concentration of the bacteria solution is $0.01-0.1 \mathrm{cfu} / \mathrm{ml})$.

The operation of bacteriostatic zone method to measure the antibacterial activity a diameter: Pipette $40 \mu \mathrm{l}$ of $E$. coli dilution (or $20 \mu \mathrm{l}$ of $S$. aureus/Salmonella enteriditis (SE) dilution) into a Petri dish with of $9 \mathrm{~cm}$, add $10 \mathrm{ml}$ of LB solid medium that has been dissolved and sterilized and cooled to $40-50{ }^{\circ} \mathrm{C}$, and shaken rapidly. Evenly, the cells were evenly dispersed. After cooled, the cells were perforated with a $2.7 \mathrm{~mm}$ diameter puncher, and $5 \mu \mathrm{l}$ of the test solution was added to each well. The sterilized fermentation medium was used as a control, let it Stand still, and inverted at $37{ }^{\circ} \mathrm{C}$ cultivated overnight, the diameter of the zone of inhibition were measured by the cross method [26].

\section{Fungi inhibition experiment}

Configuration of potato dextrose agar (PDA) medium. Method: $200 \mathrm{~g}$ potato peeled, and cut into small pieces, added water and boiled soft, filtered with gauze, added $20 \mathrm{~g}$ sucrose and $15 \mathrm{~g}$ agar, melted to make up the water to $1000 \mathrm{ml}$, and sub packaged, high pressure moist heat sterilization at $121{ }^{\circ} \mathrm{C}$ for $20 \mathrm{~min}$, and spared.

Activation of strains The culture dishes were taken out, and after been dried, they were poured into uniformly sterilized mediums, and the mediums were solidified. The strains 
were taken out from the lyophilized tube by an inoculating loop, and the mediums were streaked in the solidified mediums, and then put in a constant temperature incubator for cultivation at $28^{\circ} \mathrm{C}$ for $48 \mathrm{~h}$ and spared.

Collection of spores The 3-5 ml sterilized distilled water was added to the fungus plate covered with mature spores, gently scribed the surface with the inoculating loop, then pipetted the spore suspension through 4 layers of sterile gauze to the small triangle flask, and used $5 \mathrm{ml}$ of sterilized water. The spores on the gauze were washed down, and the spore solution was diluted to a range of $\mathrm{OD}_{600}=0.01-0.1$ (i.e., the concentration of the bacterial solution was $105-106 \mathrm{cfu} / \mathrm{ml})$.

Method of operation The $20 \mu 1$ spore suspension was added to a Petri dish with a diameter of $9 \mathrm{~cm}$, and added $10 \mathrm{ml}$ of PDA medium dissolved and cooled to $40-50{ }^{\circ} \mathrm{C}$, and shaken gently to make the spores evenly dispersed, and condensed, punched with a diameter of $2.7 \mathrm{~mm}$. The cells were perforated, and $5 \mu \mathrm{l}$ of the test solution was added to each well. The sterilized fermentation medium was used as a control, let it stand still for a while, and cultured at $30{ }^{\circ} \mathrm{C}$ overnight, and the diameter of the inhibition zone was measured [27].

\section{Minimum inhibitory concentration (MIC) determination}

Indicator bacteria: E. coli, S. aureus, A. niger. Determined by the 96-well microdilution method (resazurin as indicator) [28]. The microbial cultures of the pathogens were maintained on slants of appropriate media like the beef extract peptone medium for bacteria and the PDA solid medium for the fungal species.

Bacteria At the beginning, the micropores are all blue, if the bacteria grow and reproduce, with the bacteria Increased resazurin will turn into purple-red, and then into pink. Blue indicates that it can completely inhibit the growth of bacteria, and purple indicates that the substance has a certain antibacterial effect at this concentration, but turning pink means that the substance has no antibacterial activity or the concentration of the antibacterial substance is too low to inhibit the growth of bacteria. The turning point of color is the MIC. The lower the antibacterial concentration, the stronger the antibacterial activity of the substance. According to this point, the strongest antibacterial active component can be selected.

Mold The color of mold is opposite to that of bacteria. Royal blue indicates the growth of bacteria, and pink indicates no growth of bacteria.

\section{Determination of operating conditions for HSCCC}

Operating conditions for HSCCC include flow rate, rotational speed, injection volume, etc. In the study, try to separate by adjusting the injection volume of $100 \mathrm{mg}, 200 \mathrm{mg}$, $300 \mathrm{mg}, 400 \mathrm{mg}, 500 \mathrm{mg}$ and $600 \mathrm{mg}$; the rotation speed was adjusted to $500 \mathrm{rpm}, 550 \mathrm{rpm}, 600 \mathrm{rpm}, 650 \mathrm{rpm}$, $700 \mathrm{rpm}, 750 \mathrm{rpm}, 800 \mathrm{rpm}, 850 \mathrm{rpm}$ and $900 \mathrm{rpm}$, etc.; The flow rate was analyzed by $1.0 \mathrm{ml} / \mathrm{min}, 1.5 \mathrm{ml} / \mathrm{min}$, $2.0 \mathrm{ml} / \mathrm{min}$ and $2.5 \mathrm{ml} / \mathrm{min}$. Comparing them separately to select the operating conditions with the best separation effect.

\section{Separation and purification of antibacterial actives by HSCCC}

By screening the partition coefficient $K$ [29]. value, ethyl acetate- $n$-butanol-water (containing $3 \%$ acetic acid) was selected in a ratio of 1:4:4 (V/V) as a solvent system for countercurrent chromatography [30]. A certain proportion of the upper and lower phase solvent system was prepared by using a separating funnel. After been shaken for $12 \mathrm{~h}$, the upper and lower phases were separated, and the two phases were ultrasonically degassed for $30 \mathrm{~min}$.

A sample of $300 \mathrm{mg}$ was Dissolved and centrifuged with $3 \mathrm{ml}$ lower phase solution as a sample solution. The above phase solvent was a stationary phase of HSCCC, and the lower phase solvent was a mobile phase. Constant temperature circulation device was carried out to keep the temperature at $30{ }^{\circ} \mathrm{C}$, stationary phase flow rate was set as $15 \mathrm{ml} / \mathrm{min}$ to pump into the separation column of HSCCC, after the stationary phase was filled with the pipeline, and started the HSCCC host, and adjusted the rotation speed, and rotated clockwise. After the stationary phase was rushed into the entire column, the instrument column was opened and rotated, the rotating speed was adjusted to $850 \mathrm{rpm}$, the flow rate was set to $1.5 \mathrm{ml} / \mathrm{min}$, and the injection volume was $500 \mathrm{mg}$, after the stationary phase was stabilized in the rotating column, the mobile phase was pumped at a certain flow rate. When the upper and lower phases of the effluent began to stratify, and the upper phase of the effluent did not change, the baseline of the UV detector was observed to be stable, and the system in the entire countercurrent chromatograph had reached dynamic equilibrium [31]. At that time, the outlet of the separation column was connected to the UV detector and the chromatographic workstation, and turned on the UV lamp, and filtered the configured sample with a $0.45 \mu \mathrm{m}$ microporous membrane and injected a $2.0 \mathrm{ml}$ injection loop. The fraction collected by the chromatographic peak was at the wavelength. It was detected at $280 \mathrm{~nm}$. The fractions of the same compound obtained were combined, 
and concentrated under reduced pressure, and filtered, and designated as NL1, NL2 ... NLn, respectively. After dissolved with methanol, they were detected by HPLC.

\section{HPLC analysis and identification of HSCCC peak fractions}

HPLC conditions were as follows: column, Agilent ODS$\mathrm{C}_{18}$ column $(250 \mathrm{~mm} \times 4.6 \mathrm{~mm}, 5 \mu \mathrm{m})$; solvent $\mathrm{A}$, acetonitrile; solvent $\mathrm{B}$, water; flow rate, $0.5 \mathrm{ml} / \mathrm{min}$; injection volume, $10 \mu \mathrm{l}$; column temperature, $20^{\circ} \mathrm{C}$; wavelength, full wavelength (200-800 nm) scanning. The gradient elution program was as follows: from 0 to $20 \mathrm{~min}$, the volume fraction of acetonitrile gradually changed from 20 to $15 \%, 20$ to $25 \mathrm{~min}$, and the volume fraction of acetonitrile was changed from 15 to $20 \%$.

\section{Statistical analysis}

All data were expressed as the mean with standard deviation (SD). Statistical significance was evaluated with Duncan's multiple comparison tests at a confidence level of 95\% $(p<0.05)$ using the SPSS 22.0 software package (IBM Corp., Armonk, NY).

\section{Results and discussion}

\section{Extraction of bacteriostatic substance}

Investigating the interaction between the four factors, and finally obtain the optimal process conditions for the CPCE of $C$. oleifera actives through data analysis, are $80 \%$ ethanol, $80{ }^{\circ} \mathrm{C}$, extraction temperature, $0.4 \mathrm{Mpa}$ extraction pressure and $1 \mathrm{~h}$. extraction time. Under these conditions, the lyophilized extract inhibitory ring diameters of E. coli, S. aureus and A. niger are $13.6 \mathrm{~mm}, 15.1 \mathrm{~mm}$ and $13.8 \mathrm{~mm}$, respectively, achieving the best bacteriostatic effect; The crude extract of $C$. oleifera meal was subjected to preliminary separation of the strongest antibacterial active, the crude extract was extracted continuously with petroleum ether, ethyl acetate, $n$-butanol and water to decompress the four components. After concentration, the antibacterial activity test was carried out, and it was found that the $n$-butanol extract component had the greatest inhibition ability against E.coli, $S$. aureus and A. niger, and the diameter of the inhibition zone is $14.2 \mathrm{~mm}, 15.3 \mathrm{~mm}$ and $14.0 \mathrm{~mm}$, respectively. As shown in Table 2. So, the subsequent research was directed to the $n$-butanol extract; Preparation of $n$-butanol extract. After the $C$. oleifera meal was dried, crushed and sieved, it was subjected to CPCE under optimal conditions, and the obtained crude extract was concentrated under reduced pressure, extracted with $n$-butanol, and concentrated under reduced pressure to obtain a raw material $n$-butanol extract.

\section{HSCCC separation and peak fraction analysis}

In this experiment, HSCCC can separate the antibacterial active substances from $C$. oleifera meal in $280 \mathrm{~min}$. The operation is simple, the purity of the obtained monomers is high, and the kaempferol monomer is separated quickly and efficiently. The selection and optimization of solvent systems is a key step in HSCCC [32]. A research reported that the selection of two-phase solvent systems accounted for more than $90 \%$ of the total HSCCC workload [33]. At present, there is no sufficient theoretical basis for the choice of solvent system, and most of them are based on known solvent systems or based on experimental experience. Based on the related research and experience, four different solvent systems were used to compare the distribution coefficients of the target compounds [34]. According to the analysis results, the two antibacterial active substances can be successfully separated by ethyl acetate- $n$-butanol-water (containing $3 \%$ acetic acid) $(1: 4: 4, \mathrm{~V} / \mathrm{V})$ system, and separated from other impurity peaks. Once the composition and ratio of the HSCCC solvent system have been determined, the equipment parameters were optimized to achieve the best separation. It was known by experiment, the other operating conditions of HSCCC are flow rate $1.5 \mathrm{ml} / \mathrm{min}$, rotation speed $850 \mathrm{r} / \mathrm{min}$, injection volume $500 \mathrm{mg}$, and injection solution $3 \mathrm{ml}$, the bacteriostatic substance NL2 spectrum is shown in Fig. 1. Three peaks were collected, and the concentrated lyophilized materials were named F1, F2, and F3, respectively.

Determination of liquid phase conditions: The three components F1, F2, F3 collected were scanned at full wavelength (200-800 nm) with the longest absorption wavelength at $210 \mathrm{~nm}$. And it is known by TLC that component F1 is a highly polar substance and it is difficult to further separate it under the current liquid phase conditions [35]; F2, F3 are medium-polar substances, which can be effectively separated by a medium-polar eluent. The HPLC spectra of F1, F2 and F3 are shown in Fig. 2, respectively. Therefore, the HPCL analysis conditions are Agilent ODS-C18 column $(250 \times 4.6 \mathrm{~mm}, 5 \mu \mathrm{m})$, the mobile phase is a $40 \%$ methanol solution, $20 \mu \mathrm{l}$ is injected, and the scanning wavelength is $210 \mathrm{~nm}$.

Antibacterial activity of the antibacterial substances F1, $\mathrm{F} 2$ and F3. Through the resazurin test, the three peaks of HSCCC and MIC of eluate are shown as Table 3.

It can be seen from the above table that the MIC of the first peak F1 is higher than that of NL2, and the MIC of F2 and F3 is lower than NL2. Therefore, the antibacterial activity of F2 and F3 is relatively strong. 
Fig. 1 HSCCC spectra of optimal operating conditions

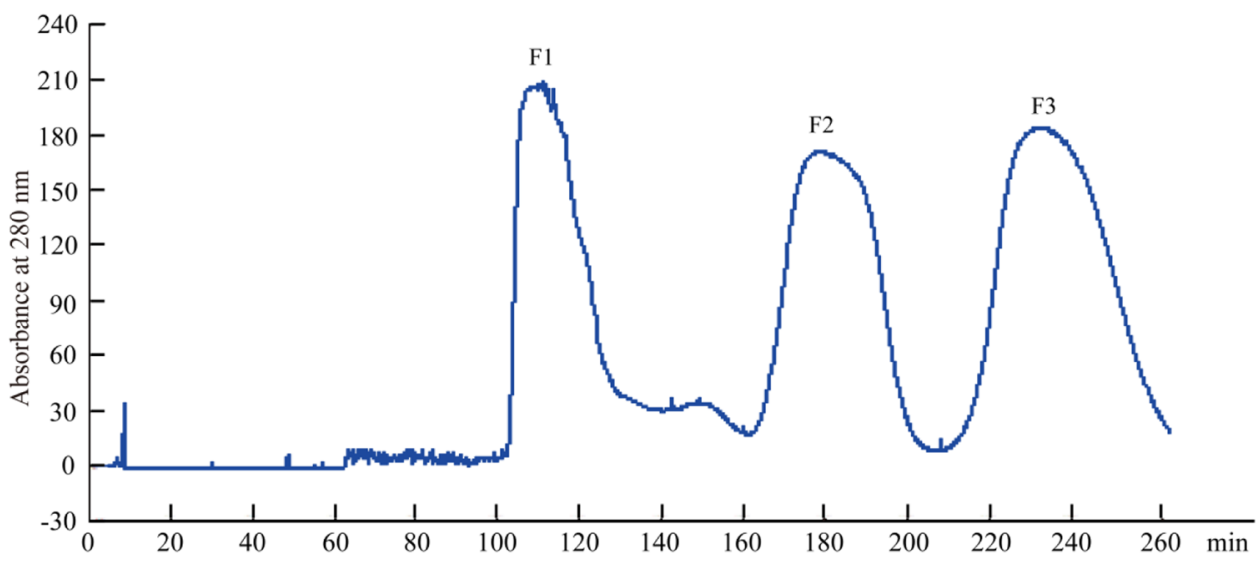

Separation preparation and antibacterial activity of F3 component of bacteriostatic substance. According to the previous analysis of liquid phase conditions, preparation liquid phase with $30 \%$ methanol, $210 \mathrm{~nm}$ detection wavelength, $10 \mathrm{ml} / \mathrm{min}$ flow rate, $50 \mu \mathrm{l}$ sample volume and $15 \mathrm{mg} / \mathrm{ml}$ sample concentration. The two substances of the F3 component can be efficiently prepared, and collected and lyophilized and named as J1, J2, respectively. The antibacterial activity of $\mathrm{J} 1$ and $\mathrm{J} 2$ are shown in Table 4 . The content of $\mathrm{J} 1$ is not only extremely low, but its antibacterial activity is not as good as J2 and not as good as F2.

Three very pure antibacterial active substances were isolated, which were $\mathrm{F} 2, \mathrm{~J} 1$ and $\mathrm{J} 2$, respectively, and the contents of $\mathrm{F} 2$ and $\mathrm{J} 2$ were high. The MIC of F2 against E. coli, S. aureus and A. niger are $20.71 \mu \mathrm{g} / \mathrm{ml}, 35.82 \mu \mathrm{g} /$ $\mathrm{ml}$ and $47.43 \mu \mathrm{g} / \mathrm{ml}$, respectively; The MIC of J2 against E. coli, S. aureus and A. niger are $18.33 \mu \mathrm{g} / \mathrm{ml}, 25.68 \mu \mathrm{g} /$ $\mathrm{ml}$ and $42.63 \mu \mathrm{g} / \mathrm{ml}$, respectively; The antibacterial activity of $\mathrm{J} 1$ is not strong. The combination of HSCCC and HPLC can efficiently and rapidly separate the antibacterial active substances $\mathrm{F} 2$ and $\mathrm{J} 2$ from $C$. oleifera meal.

\section{Structural identification}

\section{Structural identification of bacteriostatic substance F2}

Mass spectrometry and nuclear magnetic data are shown in the Table 5.

Analysis of bacteriostatic substance F2: In the LC-ESI-MS spectrum, the first-order positive ion mode gives $\mathrm{m} / \mathrm{e}$ of $757.2[\mathrm{M}+\mathrm{H}]^{+}, 779.11[\mathrm{M}+\mathrm{Na}]^{+}$and the firstorder negative ion mode detection gives $\mathrm{m} / \mathrm{z}$ of 755.1 [The $\mathrm{MH}]$-excimer ion peak indicates that the compound has a molecular weight of 756. Compare J2 kaempferol 3- $O$-[ $[\beta$-Dxylopyranosyl- $(1 \rightarrow 2)$ - $\alpha$-L-rhamnopyranosyl- $(1 \rightarrow 6)]-\beta$-Dglucopyranoside, the molecular weights of the two are exactly 30 , which indicates that the structure of the two is very similar, and may be converted from xylose (pentanaldehyde) in the $\mathrm{J} 2$ structure to a hexose.

Further spectroscopic analysis of the two mass spectra of the two compounds confirmed the above speculation. Compound F2 was subjected to secondary cleavage with $\mathrm{m} / \mathrm{z}$ of $757.2[\mathrm{M}+\mathrm{H}]{ }^{+}$as the parent ion, and $\mathrm{m} / \mathrm{z}$ is 595.4, 448.9 , and 287.1, and the excimer ion of compound $\mathrm{J} 2$ is $727.1[\mathrm{M}+\mathrm{H}]^{+}$. Separation of the parent ion for secondary cleavage, the same three sub-ions appear above, indicating that the compound $\mathrm{F} 2$ secondary ion $\mathrm{m} / \mathrm{z} 595.4$ is $\left[\mathrm{M}+\mathrm{H}-\mathrm{C}_{6} \mathrm{H}_{10} \mathrm{O}_{5}\right]^{+}$molecule first loses a six-carbon aldose; $\mathrm{m} / \mathrm{z} 448.9$ is $\left[\mathrm{M}+\mathrm{H}-\mathrm{C}_{6} \mathrm{H}_{10} \mathrm{O}_{5}-\mathrm{C}_{6} \mathrm{H}_{10} \mathrm{O}_{4}\right]^{+}$, and the molecule loses the rhamnose moiety after losing the hexose aldose; $m / z 287.1$ is $\left[\mathrm{C}_{15} \mathrm{H}_{10} \mathrm{O}_{6}+\mathrm{H}\right]^{+}$, which proves that the aglycone is kaempferol.

The ${ }^{1} \mathrm{H}-\mathrm{NMR}$ of the compound was analyzed, and the saccharide ring proton $\delta 4.74(1 \mathrm{H}, \mathrm{d}, J=7.2 \mathrm{~Hz})$ was compared with $\mathrm{J} 2$, indicating that the hexose aldose is glucose, and thus, in combination with known literature reports [36], The F2 and J2 substances are the main biological active substances in the samovar, and the molecular formula $\mathrm{C}_{3} \mathrm{H}_{40} \mathrm{O}_{20}$ of the compound $\mathrm{F} 2$ can be derived, which is kaempferol 3-O-[ $\beta$-D-glucopyranosyl- $(1 \rightarrow 2)-\alpha$-Lrhamnopyranosyl-( $1 \rightarrow 6)]-\beta$-D-glucopyranoside, the structural formula is shown in Fig. 3.

\section{Structural identification of bacteriostatic substance J2}

Mass spectrometry and nuclear magnetic data are shown in the Table 5.

Analysis of bacteriostatic substance J2: In ESI-MS, the positive ion mode gave $\mathrm{m} / z$ of $727.1[\mathrm{M}+\mathrm{H}]^{+}$and negative ion mode detection gave a $\mathrm{m} / \mathrm{z}$ of $725.5[\mathrm{M}-\mathrm{H}]^{-}$excimer ion peak, suggesting that the compound has a molecular weight of 726 . Analysis of the compound by ${ }^{1} \mathrm{H}-\mathrm{NMR}$, $\delta 8.04(2 \mathrm{H}, \mathrm{d}, J=8.0 \mathrm{~Hz})$ and $6.90(2 \mathrm{H}, \mathrm{d}, J=8.0 \mathrm{~Hz})$ proved that the flavonoid quinone $\mathrm{B}$ ring was in the $4^{\prime}$ substitution mode; $\delta 6.20(1 \mathrm{H}, \mathrm{d}, J=1.8 \mathrm{~Hz})$ and $6.38(1 \mathrm{H}$, 
Fig. 2 The HPLC chromatograms of NL2, F2 and F3 a

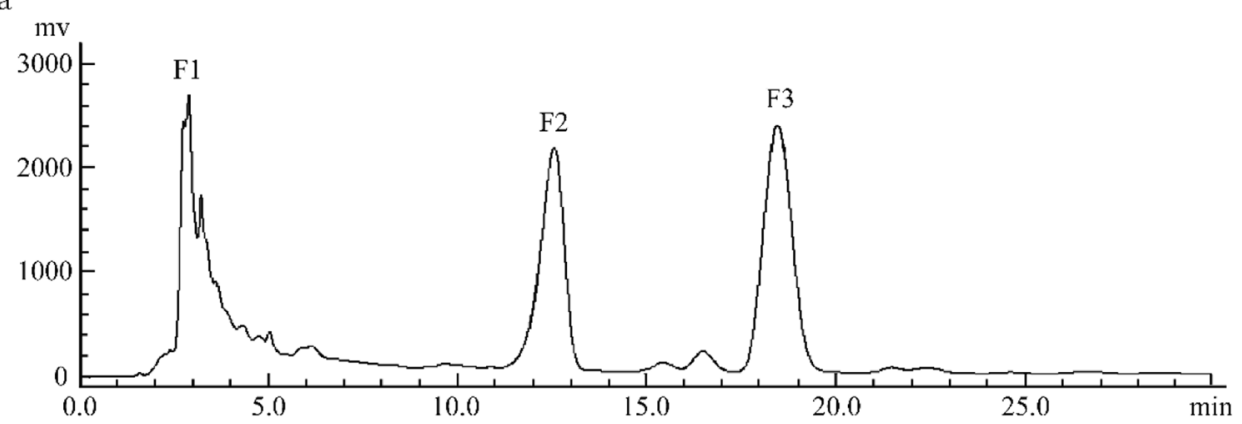

b

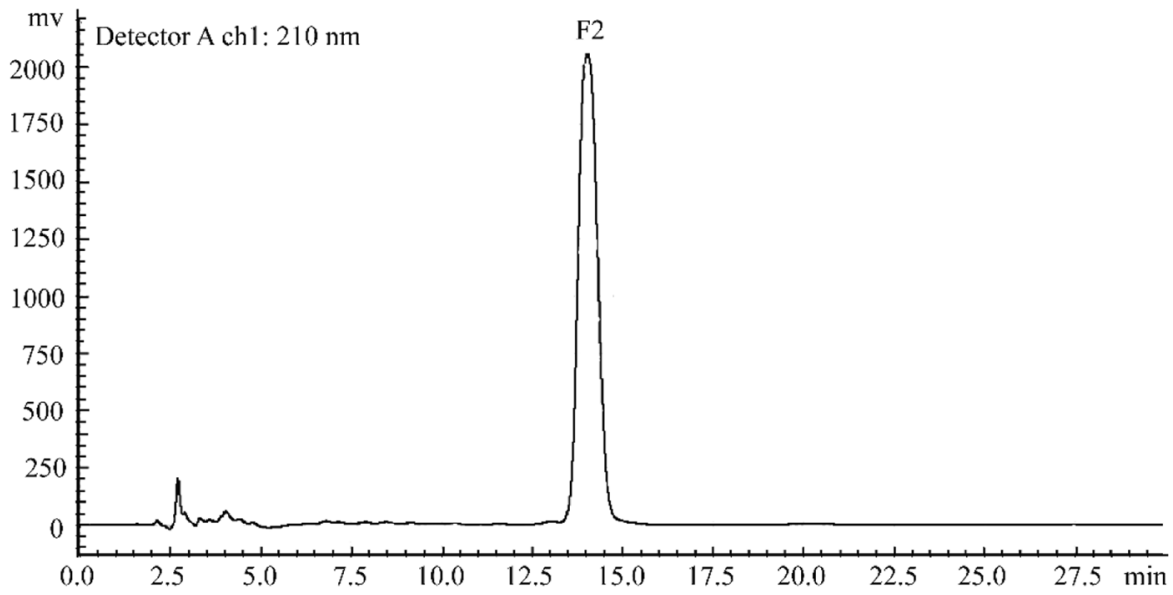

C

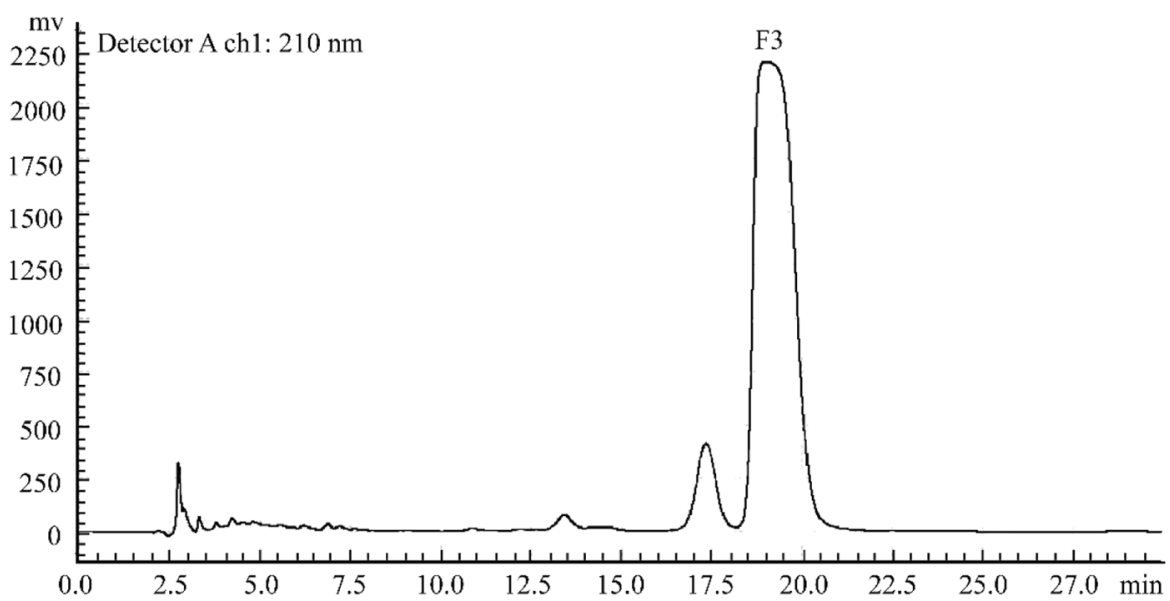

$\mathrm{d}, J=1.8 \mathrm{~Hz})$ indicate that the A ring contains 5,7 dihydroxy substitution; $\delta 4.49$ (1H, overlapped), 4.77 (1H, overlapped) and $5.40(1 \mathrm{H}, \mathrm{d}, J=7.2 \mathrm{~Hz})$ suggesting that the molecule contains three sugar molecules, of which $\delta 1.10$ $(3 \mathrm{H}, \mathrm{d}, J=6.0 \mathrm{~Hz})$ indicates that there is a rhamnose. In ${ }^{13} \mathrm{C}-\mathrm{NMR}$ (DEPT) [25], 11 consecutively appeared in the range of $\delta 100.8(\mathrm{CH}), 102.2(\mathrm{CH}), 105.2(\mathrm{CH}), 68.2\left(\mathrm{CH}_{2}\right)$, $66.5\left(\mathrm{CH}_{2}\right), 17.9\left(\mathrm{CH}_{3}\right)$ and $\delta 69.7-82.0$. Oxygen carbon $(\mathrm{CH})$, the above further confirmed that the compound $\mathrm{Y} 2$ is a flavonoid trisaccharide, and at the same time, the 17 sugar ring carbon signals were compared and confirmed to be pyrazyl rhamnose, glucopyranose and pyranose, respectively. It can be confirmed that the molecular formula of the compound is $\mathrm{C}_{32} \mathrm{H}_{38} \mathrm{O}_{19}$, the degree of unsaturation is 14 , and the aglycone is kaempferol. It can be seen that $\delta \mathrm{H}$ 5.40 (Glu-1") and $\delta \mathrm{C} 134.8$ (C-5), $\delta \mathrm{H} 4.49$ (Rha-1") and $\delta \mathrm{C}$ 68.2 (Glu-6"), $\delta \mathrm{H} 4.77$ (Xyl-1)") is remotely related to $\delta \mathrm{C}$ 82.0 (Glu-2"), demonstrating that the order of linkage of the three sugar molecules is $\beta$-D-xylopyranoside- $(1 \rightarrow 2)-[\alpha-\mathrm{L}-$ rhamnose- $(1 \rightarrow 6)]-\beta$-D-glucose, combined with the above analysis, and compared with literature data, determined that compound $\mathrm{J} 2$ is kaempferol 3- $O-[\beta-\mathrm{D}-$ 


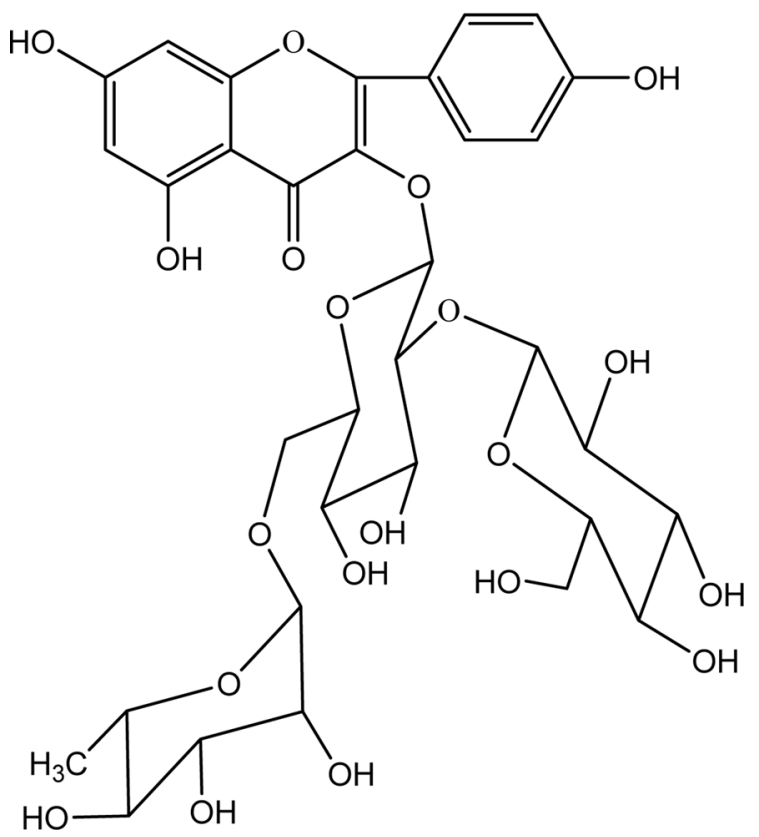

Fig. 3 Chemical structure of F2

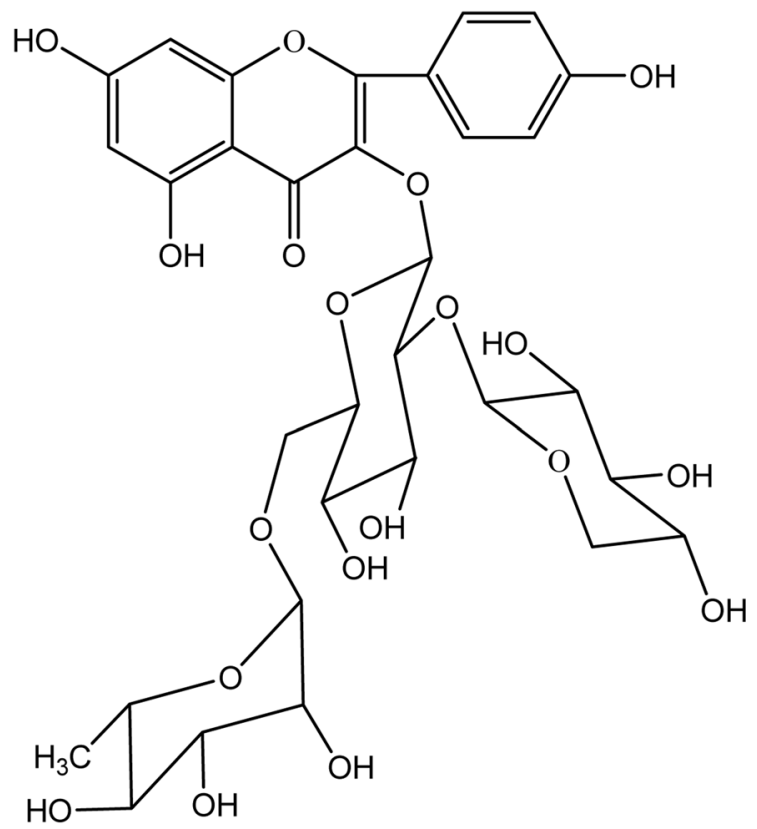

Fig. 4 Chemical structure of J2

xylopyranosyl-( $1 \rightarrow 2)$ - $\alpha$-L-rhamnopyranosyl-( $1 \rightarrow 6)]-\beta$-Dglucopyranoside, the chemical structure is shown in Fig. 4.

\section{Study on antibacterial activity of antibacterial substance F2}

Many studies have found that kaempferol, some glycosides of kaempferol and plants containing kaempferol have strong resistance to bacteria, fungi, viruses, and protozoa. The antibacterial activity of kaempferol can already be observed in vivo. Mongolian gerbils were orally inoculated with Helicobacter pylori 4 weeks after oral administration of kaempferol. After 10 days of taking kaempferol, it was observed that kaempferol significantly reduced the number of Helicobacter pylori colonies in the gerbil stomach [37]. In addition, oral administration of kaempferol also significantly increased the survival rate of mice infected with Klebsiella pneumoniae. In addition, kaempferol and its glycosides can also cooperate with antibiotics (such as rifampicin, vancomycin, methicillin, erythromycin, and clindamycin) against antibiotic-resistant bacteria [38] Kaempferol interferes with certain enzymes that are essential for the growth or toxicity of certain fungi. Chitin is a structural polysaccharide of fungal cell walls, synthesized by chitin synthase, which is essential for the integrity of fungi. In vitro studies have found that kaempferol inhibits chitin synthase II and prevents fungal cell division. In addition, kaempferol has a certain inhibitory effect on the synthesis of melanin [39], which is a causative agent of pathogenic fungi and a known target of antifungal compounds. There are also some studies that prove that kaempferol can affect the extracellular enzyme of Candida albicans, which is a virulence factor responsible for the infiltration of yeast into host cells. It was also found that administration of kaempferol to animals infected with systemic $C$. albicans can increase the number of survivals.

Compared with other flavonoid natural antioxidants, kaempferol has better antibacterial effect. The minimum inhibitory concentration MIC of kaempferol isolated from the methanol extract of buckthorn against two Gram-negative and four Gram-positive pathogens is $2.4 \mu \mathrm{g} / \mathrm{ml}$ [40]; Dimer variants of apigenin have a MIC of $5 \mu \mathrm{g} / \mathrm{ml}$ for the fungal pathogens $C$. albicans, Saccharomyces cerevisiae and Trypanosoma beige [41]; apigenin identified from the half-branch S (Solanaceae) performed on 20 strains of MRSA The antimicrobial activity MIC was 3.9-15.6 $\mu \mathrm{g} /$ $\mathrm{ml}$ [42].

The antibacterial effect of flavonoids may be related to its structure. Attributable to cell wall permeability and porins in the outer membrane of microorganisms, these compounds seem to block the charge of amino acids in porins. A comparison of the above properties indicates that flavonoids with free hydroxyl groups at C-5 and C-7 of ring $\mathrm{A}$ are more active, and studies of their synthetic analogues support this conclusion [43]. The bacteriostatic activity of flavonoids may also be attributed to their ability to complex with extracellular and soluble proteins and then with the bacterial cell wall. The same author also suggested that more lipophilic flavonoids may also damage microbial membranes [44]. 


\section{Broad-spectrum antibacterial activity of bacteriostatic substance F2}

Since the sample amount of F2 is relatively abundant, F2 will be used in subsequent studies. Through agar plate bacteriostatic method, it was found that $\mathrm{F} 2$ has good antibacterial activity against $E$. coli, $S$. aureus, $S E$, Bacillus thuringiensis $(B t)$, A. niger and Rhizopus nigricans (R. nigricans), and the antibacterial effect against bacteria is obviously stronger than that on fungi. The bacteriostatic effect, as shown in Fig. 5, the diameter of the inhibition zone of $\mathrm{F} 2$ against $E$. coli, $S$. aureus, Bt, and $S E$ is significantly larger than the diameter of the inhibition zone of A. niger and $R$. nigricans.

The antibacterial substance F2 has a strong, broad-spectrum antibacterial effect by the resazurin method, at the same concentration, its antibacterial effect against bacteria is stronger than that of fungi, and compared with the MIC of kanamycin, it is known that the MIC of kanamycin against
E. coli is $21.25 \mu \mathrm{g} / \mathrm{ml}$, which is equivalent to the antibacterial effect of F2 component; the MIC for $S E$ is $62.5 \mu \mathrm{g} / \mathrm{ml}$, and the $\mathrm{F} 2$ component is 2 times stronger than kanamycin; The MIC of $B t$ is $57.95 \mu \mathrm{g} / \mathrm{ml}$, the antibacterial activity of F2 component against $B t$ is nearly 4 times stronger than that of kanamycin; the MIC of $S$. aureus is $45.5 \mu \mathrm{g} / \mathrm{ml}$, and the F2 fraction is slightly stronger than it. It can be seen that the F2 part of the bacteriostatic substance has a significant antibacterial effect, and the antibacterial effect of F2 against A. niger is stronger than that of kanamycin, but the antibacterial effect against $R$. nigricans is much weaker than that of kanamycin. As shown in Table $6(p<0.05)$.

\section{Effect of different temperature treatments on antibacterial activity of antibacterial substance $F 2$}

As can be seen from Fig. 6, the bacteriostatic active substance $\mathrm{F} 2$ was treated at $-19{ }^{\circ} \mathrm{C}, 4^{\circ} \mathrm{C}, 60^{\circ} \mathrm{C}, 80^{\circ} \mathrm{C}, 90^{\circ} \mathrm{C}$,

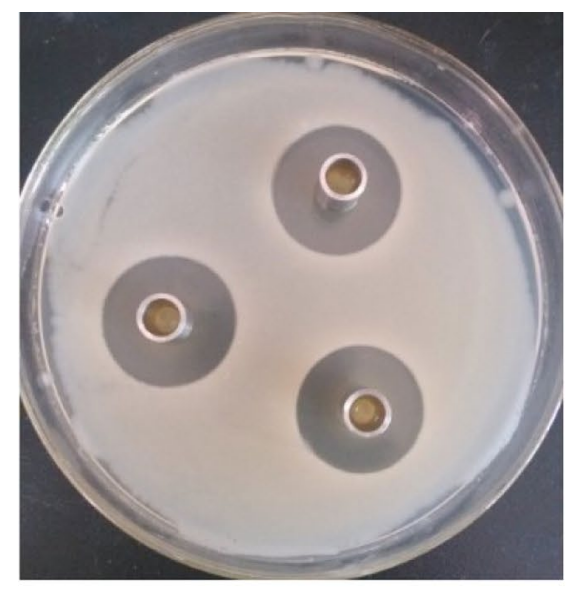

a E.coli

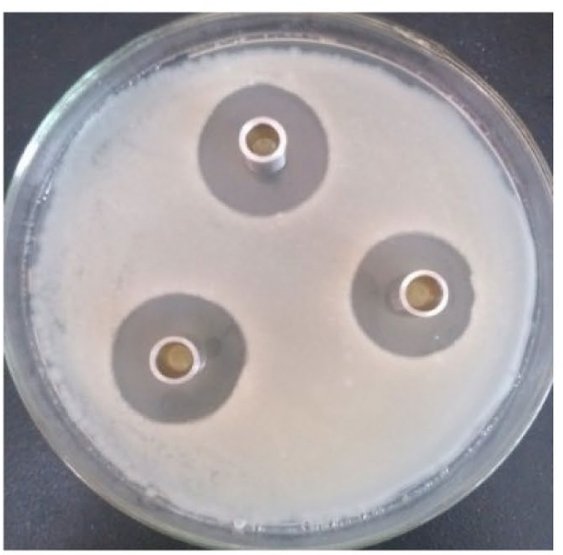

d SE

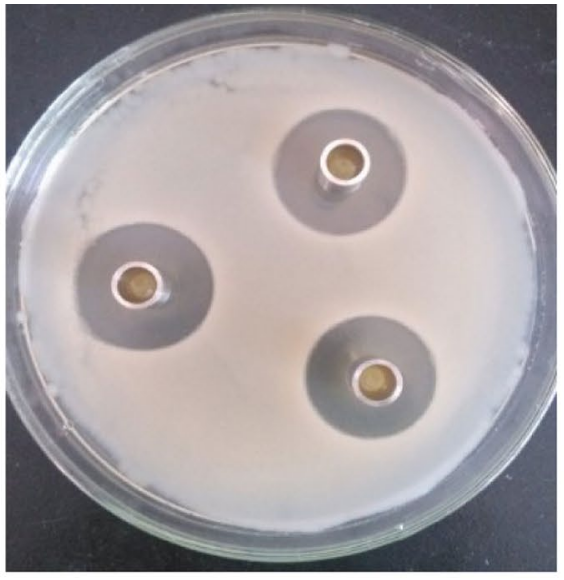

b S. aureus

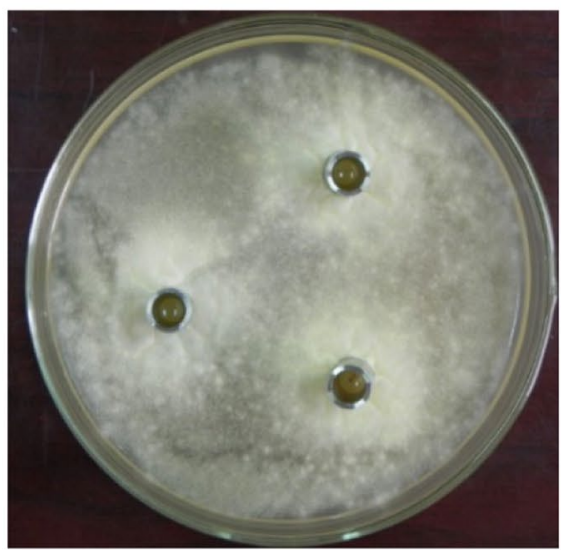

e A. niger

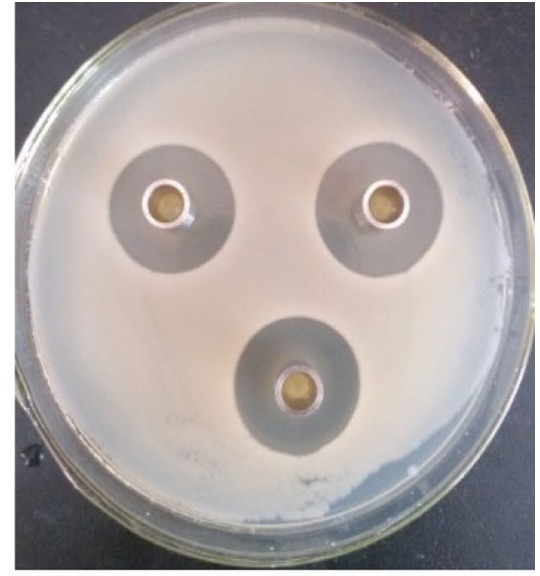

$\mathrm{c} \mathrm{Bt}$

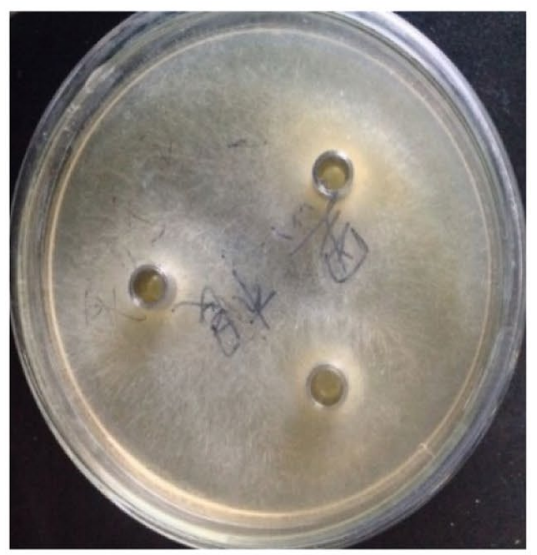

f R.nigricans

Fig. 5 Antibacterial effect of antibacterial substance F2 on some bacteria and mold 


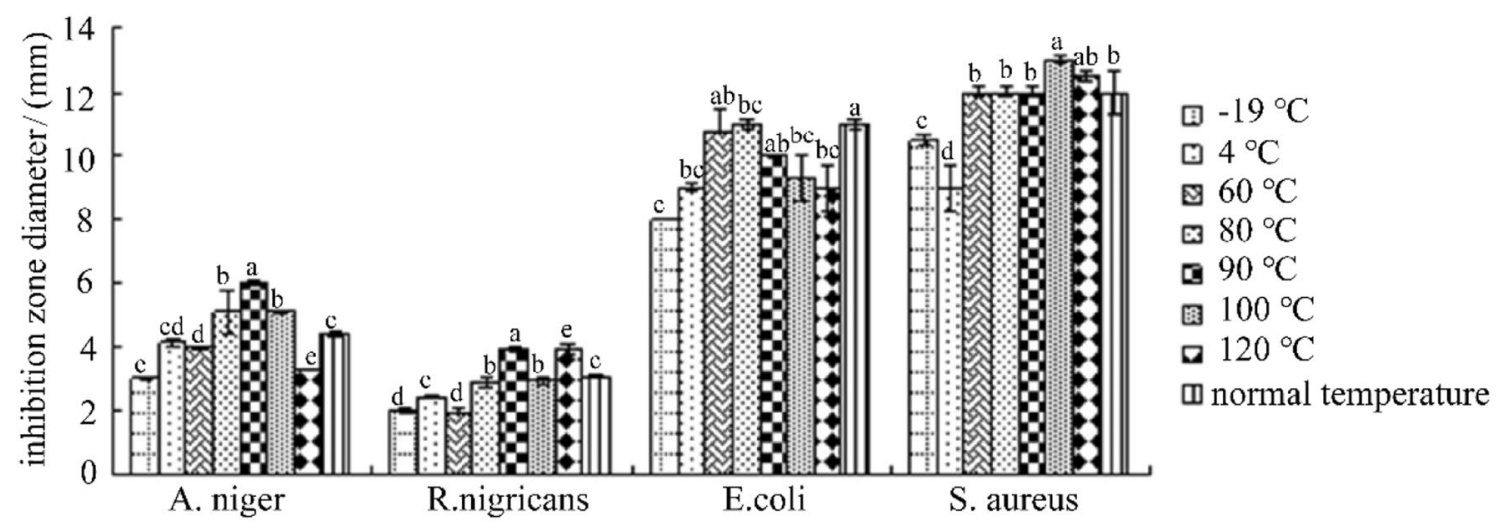

Fig. 6 Effect of heat treatment on the antibacterial activity of F2. (Different letters indicate significant differences $(P<0.05)$, the same below)

$100{ }^{\circ} \mathrm{C}$ and $120^{\circ} \mathrm{C}$ for $20 \mathrm{~min}$, and compared with the control, against E. coli, S. aureus, A. niger, R. nigricans There was no significant change in bacterial effect, indicating that the antibacterial active substance F2 has good thermal stability.

\section{Effect of different $\mathrm{pH}$ on antibacterial activity of antibacterial substance F2}

It can be seen from Fig. 7 that $\mathrm{F} 2$ is affected by the $\mathrm{pH}$ of the medium. When the $\mathrm{pH}$ is $1.0-7.0$, with the $\mathrm{pH}$ was increasing, the antibacterial effect of $\mathrm{F} 2$ increasing too. When the $\mathrm{pH}$ is $8.0-12.0$, the effect on the fungi is reduced or even it disappeared completely, but the bacteriostatic effect on bacterial did not change much. This may be due to the destruction of the structure of the F2 bacteriostatic active substance by the medium environment of peracid or over-alkali, and even its inactivation [45]. The active substance $\mathrm{F} 2$ has a relatively stable action at a $\mathrm{pH}$ of 6.0 or neutral. In general, the active ingredient in the $C$. oleifera meal extract is stable under acidic environment than in alkaline conditions.

\section{Effect of ultraviolet irradiation on antibacterial activity of bacteriostatic substance F2}

It can be seen from Fig. 8 that after the ultraviolet irradiation of $\mathrm{F} 2$ for 5-30 min at different times, the antibacterial effect of the F2 has no obvious change, and the antibacterial activity has no effect. It is indicated that the UV irradiation has little effect on the antibacterial active substances of $C$. oleifera meal extract in the range of UV light intensity and irradiation time selected by the experiment, and the extract has good stability to UV.

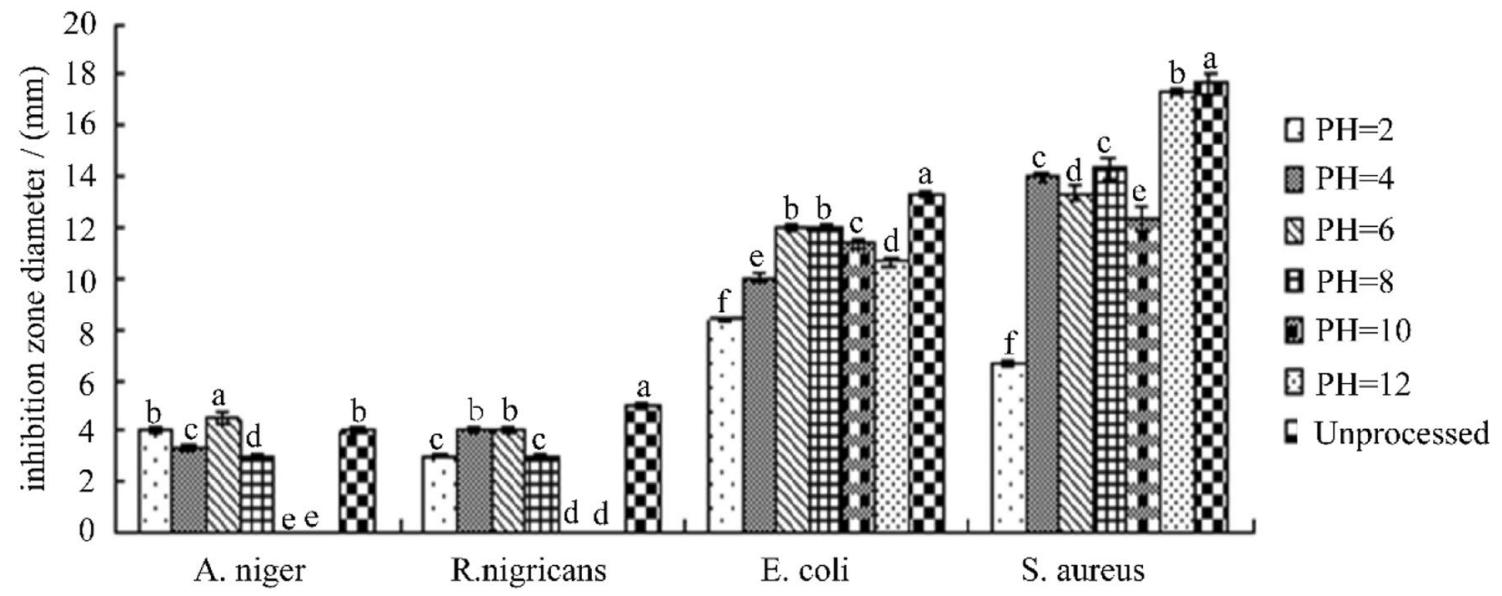

Fig. 7 Effects of different $\mathrm{pH}$ on the inhibitory activity of F2 


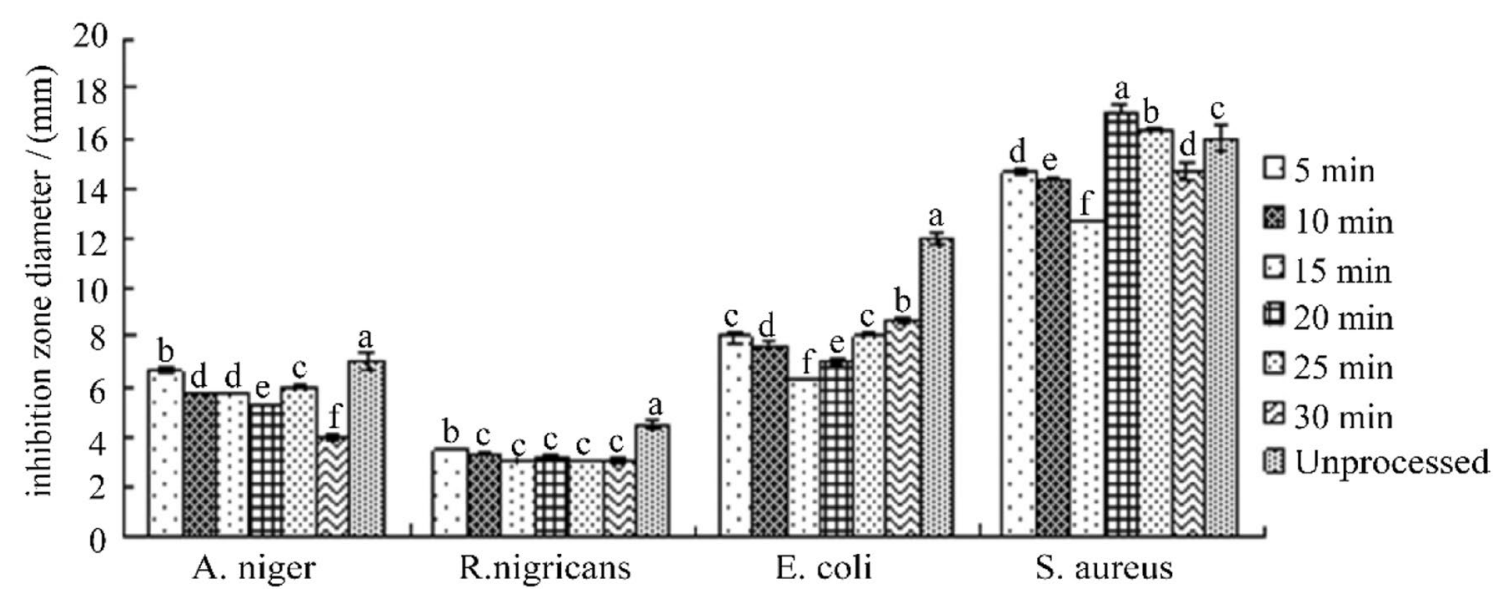

Fig. 8 Effect of UV irradiation on the antibacterial activity of F2

\section{Effect of light on antibacterial activity of bacteriostatic substance $F 2$}

It can be seen from Fig. 9 that F2 has no significant change in bacteriostatic effect compared with the control after light treatment at different times, and does not show a significant tendency to affect the activity by illumination time, indicating that $\mathrm{F} 2$ is in the selected illumination time range. Within the light, it can exhibit relatively stable antibacterial activity under the action of light.

\section{Effect of different metal ions on antibacterial activity of antibacterial substance F2}

It can be seen from Fig. 10 that the antibacterial effect of $\mathrm{F} 2$ in $\mathrm{Na}^{+}, \mathrm{K}^{+}, \mathrm{Ba}^{2+}, \mathrm{Mg}^{2+}, \mathrm{Ca}^{2+}$ and $\mathrm{Fe}^{3+}$ solutions has no significant change compared with the control, and its antibacterial activity does not show obvious under the action of different metal ions. The change of antibacterial activity indicates that $\mathrm{F} 2$ has a relatively stable antibacterial activity within the selected metal ion concentration range.

\section{Conclusions}

In summary, two pure antibacterial active substances (F2 and $\mathrm{J} 2$ ) were successfully obtained by the combination of CPCE and HSCCC, there were isolated with high purities (over 90\%). The chemical structures of the obtained bacteriostatic monomer compounds $\mathrm{F} 2$ and $\mathrm{J} 2$ were identified by mass spectrometry and NMR. By comparison, and the two monomer substances are flavonoids. The molecular weight of $\mathrm{F} 2$ is 756 , and its molecular formula is $\mathrm{C}_{33} \mathrm{H}_{40} \mathrm{O}_{20}$, which is kaempferol 3- $O$-[ $\beta$-D-glucopyranosyl- $(1 \rightarrow 2)-\alpha$-Lrhamnopyranosyl-( $1 \rightarrow 6)$ ]- $\beta$-D-glucopyranoside; J2 has a molecular weight of 726 with a molecular formula of $\mathrm{C}_{32} \mathrm{H}_{38} \mathrm{O}_{19}$, which is kaempferol 3- $O$-[ $[\beta$-Dxylopyranosyl-( $(\rightarrow 2)$ - $\alpha$-L-rhamnopyranosyl- $(1 \rightarrow 6)]-\beta$-D-

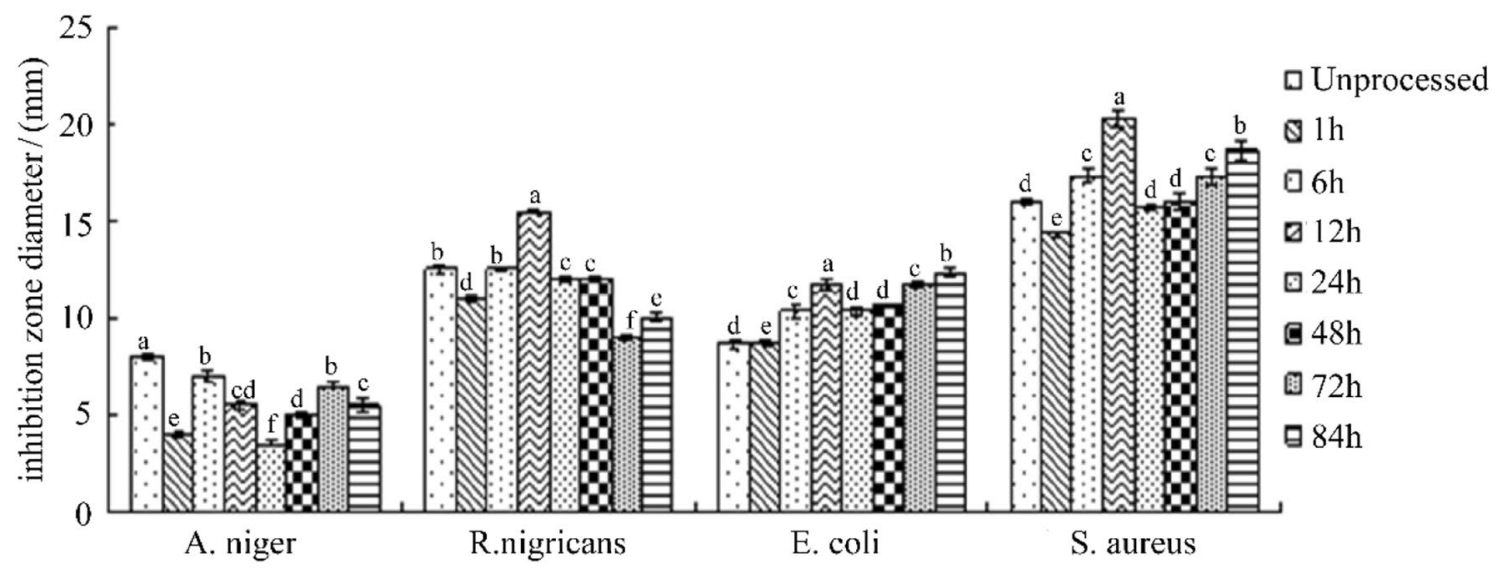

Fig. 9 Effect of light on the antibacterial activity of F2 


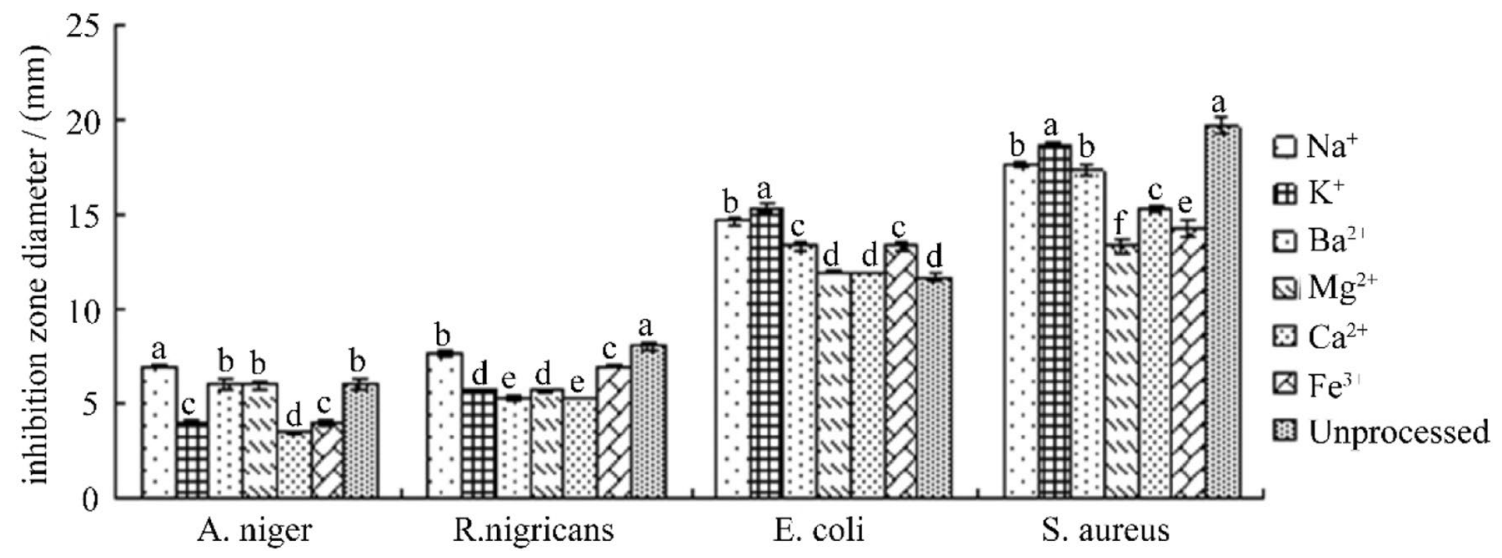

Fig. 10 Effect of different metal ions on the antibacterial activity of F2

glucopyranoside, which were for the first time isolated from C. oleifera meal. Two identified kaempferol have strong antibacterial activity. Furthermore, the antibacterial stability of F2 were finally confirmed: F2 showed broad spectrum antibacterial activity E.coli, S. aureus, SE, Bt and A. niger, R.nigricans; it is stable in the temperature range of -19 to $120{ }^{\circ} \mathrm{C}$ for $20 \mathrm{~min}$; at the same time, it is relatively stable in the $\mathrm{pH}$ range of $2.0-8.0$, while the $\mathrm{pH}$ exceeds 8.0 , the antibacterial activity almost disappeared; it also has stable antibacterial activity under different time light (within $80 \mathrm{~h}$ ) and ultraviolet light (within $30 \mathrm{~min}$ ); in addition, it shows a relatively stable antibacterial activity in the solution of $\mathrm{Na}^{+}$, $\mathrm{K}^{+}, \mathrm{Ba}^{2+}, \mathrm{Mg}^{2+}, \mathrm{Ca}^{2+}$ and $\mathrm{Fe}^{3+}$. Therefore, it can be used as a potential food additive to reduce the risk of chronic diseases. Therefore, by using CPCE and HSCCC, high-purity effective bacteriostatic compounds can be separated from $C$. oleifera, which will help to improve the functional characteristics and economic value of this agricultural food waste.

Acknowledgments This study was supported financially by the Guangdong Province key areas R \& D project (Grant number: 2019B020238003).

\section{Compliance with ethical standards}

Conflict of interest All authors declare that they have no known competing financial interests or personal relationships that could have appeared to influence the work reported in this paper.

Compliance with ethics requirements This article does not contain any studies with human or animal subjects.

\section{Appendix}

Tables 1, 2, 3, 4, 5 and 6.

Table $1 \mathrm{~L}_{9}\left(3^{4}\right)$ factors and levels of orthogonal experiment

\begin{tabular}{lllll}
\hline Level & Factor & & & \\
\cline { 2 - 5 } & $\begin{array}{l}\text { (A) Ethanol } \\
\text { concentration } \\
(\%)\end{array}$ & $\begin{array}{l}\text { (B) Extrac- } \\
\text { tion time } \\
\text { (h) }\end{array}$ & $\begin{array}{l}\text { (C) Extrac- } \\
\text { tion pressure } \\
(\mathrm{MPa})\end{array}$ & $\begin{array}{l}\text { (D) Extraction } \\
\text { temperature } \\
\left({ }^{\circ} \mathrm{C}\right)\end{array}$ \\
\hline 1 & 70 & 1 & 0.4 & 70 \\
2 & 80 & 2 & 0.5 & 80 \\
3 & 90 & 3 & 0.6 & 90 \\
\hline
\end{tabular}

Table 2 Antibacterial activity of different polarity $(X \pm \mathrm{SD}$, $n=3$ )

\begin{tabular}{|c|c|c|c|c|c|}
\hline \multirow[t]{2}{*}{ Test strain } & \multicolumn{5}{|c|}{ Inhibition zone size diameter(mm) } \\
\hline & NL2 & SYM & YSYZ & $\mathrm{ZDC}$ & SZF \\
\hline E. coli & $13.6 \pm 0.13$ & $11.3 \pm 0.09$ & $11.4 \pm 0.09$ & $14.2 \pm 0.15$ & $13.5 \pm 0.12$ \\
\hline S. aureus & $15.1 \pm 0.11$ & $11.5 \pm 0.12$ & $13.2 \pm 0.11$ & $15.3 \pm 0.21$ & $13.9 \pm 0.15$ \\
\hline A. niger & $13.8 \pm 0.14$ & $9.3 \pm 0.08$ & $12.5 \pm 0.15$ & $14.0 \pm 0.13$ & $13.3 \pm 0.05$ \\
\hline
\end{tabular}


Table 3 Antibacterial activity of NL2 components and its isolates $(X \pm \mathrm{SD}, n=3)$

\begin{tabular}{lrlll}
\hline Test strain & \multicolumn{4}{l}{ MIC $(\mu \mathrm{g} / \mathrm{ml})$} \\
\cline { 2 - 5 } & NL2 & F1 & F2 & F3 \\
\hline E. coli & $35.23 \pm 0.08$ & $42.56 \pm 0.13$ & $20.71 \pm 0.11$ & $22.23 \pm 0.17$ \\
S. aureus & $55.87 \pm 0.11$ & $69.04 \pm-0.08$ & $35.82 \pm 0.14$ & $38.35 \pm 0.17$ \\
A. niger & $79.0 \pm 0.14-$ & $47.43 \pm 0.16$ & $44.65 \pm 0.18$ \\
\hline “_” means no obvious antibacterial effect & &
\end{tabular}

Table 4 Antibacterial activity of component F3 and its isolates $(X \pm \mathrm{SD}, n=3)$

\begin{tabular}{llll}
\hline Test strain & \multicolumn{2}{l}{ MIC $(\mu \mathrm{g} / \mathrm{ml})$} & $\mathrm{J} 2$ \\
\cline { 2 - 4 } & $\mathrm{F} 3$ & $\mathrm{~J} 1$ & $18.33 \pm 0.7$ \\
\hline E. coli & $22.23 \pm 0.10$ & $132.44 \pm 0.25$ & $25.68 \pm 0.12$ \\
S. aureus & $38.35 \pm 0.13$ & $139.04 \pm 0.23$ & $42.63 \pm 0.22$ \\
A. niger & $44.65 \pm 0.15$ & - & \\
\hline
\end{tabular}

Table $5{ }^{13} \mathrm{C}$ NMR and partial ${ }^{1} \mathrm{H}$ NMR spectral data for compounds F2 and J2

\begin{tabular}{|c|c|c|c|c|c|c|}
\hline $\mathrm{C}$ & $\mathrm{F} 2$ & $\mathrm{~J} 2$ & Ref. [2] & $\mathrm{H}$ & 1 & 2 \\
\hline 2 & 158.83 & 158.47 & 154.66 & & & \\
\hline 3 & 135.89 & 134.82 & 132.59 & & & \\
\hline 4 & 180.32 & 179.47 & 176.94 & & & \\
\hline 5 & 162.46 & 162.98 & 161.07 & & & \\
\hline 6 & 101.38 & 99.94 & 99.31 & 6 & 3.798 & 3.998 \\
\hline 7 & 165.57 & 165.76 & 165.05 & & & \\
\hline 8 & 96.99 & 94.91 & 93.85 & 8 & 3.793 & 3.987 \\
\hline 9 & 160.47 & 158.86 & 156.48 & & & \\
\hline 10 & 106.88 & 105.78 & 102.78 & & & \\
\hline $1^{\prime}$ & 123.97 & 122.93 & 120.89 & & & \\
\hline $2^{\prime}$ & 133.65 & 132.39 & 130.71 & $2^{\prime}$ & 4.983 & 5.40 \\
\hline $3^{\prime}$ & 117.69 & 116.24 & 115.13 & $3^{\prime}$ & 4.796 & 4.794 \\
\hline $4^{\prime}$ & 161.11 & 161.37 & 161.00 & & & \\
\hline $5^{\prime}$ & 117.69 & 116.24 & 115.13 & $5^{\prime}$ & 4.796 & 4.794 \\
\hline $6^{\prime}$ & 133.65 & 132.39 & 130.71 & $6^{\prime}$ & 4.983 & 5.40 \\
\hline $\mathrm{CC}$ & $\alpha$-L-Rhamno & $\alpha$-L-Rhamno & Ref. [2] & $\mathrm{H}$ & 1 & 2 \\
\hline $1^{\prime \prime}$ & 103.09 & 102.15 & & $1^{\prime \prime}$ & 3.821 & 4.511 \\
\hline $2^{\prime \prime}$ & 72.69 & 72.29 & & & & \\
\hline $3^{\prime \prime}$ & 72.49 & 72.07 & & & & \\
\hline $4 "$ & 74.35 & 73.87 & & & & \\
\hline $5^{\prime \prime}$ & 71.09 & 69.75 & & & & \\
\hline $6^{\prime \prime}$ & 19.05 & 17.07 & & $6^{\prime \prime}$ & 3.354 & 3.526 \\
\hline $\mathrm{CC}$ & $\beta$-D-Gluco (A) & $\beta$-D-Gluco & $\beta$-D-Gluco & $\mathrm{H}$ & 1 & 2 \\
\hline $1^{\prime \prime}$ & 102.43 & 100.83 & 97.88 & $1^{\prime \prime}$ & 3.806 & 4.006 \\
\hline $2^{\prime \prime}$ & 81.60 & 82.08 & 81.73 & & & \\
\hline $3 "$ & 78.42 & 78.19 & 76.04 & & & \\
\hline $4^{\prime \prime}$ & 71.49 & 71.42 & 69.53 & & & \\
\hline $5^{\prime \prime}$ & 78.65 & 77.05 & 76.78 & & & \\
\hline $6^{\prime \prime}$ & 69.53 & 68.13 & 60.48 & & & \\
\hline $\mathrm{C}$ & $\beta$-D-Gluco (B) & $\beta$-D-Xylo & $\beta$-D-Xylo & $\mathrm{H}$ & 1 & 2 \\
\hline $1^{\prime \prime}$ & 104.70 & 105.25 & 104.44 & $1^{\prime \prime}$ & 4.448 & 4.783 \\
\hline $2^{\prime \prime}$ & 76.07 & 74.80 & 73.78 & & & \\
\hline $3^{\prime \prime}$ & 77.11 & 76.94 & 76.04 & & & \\
\hline $4^{\prime \prime}$ & 72.16 & 71.01 & 69.37 & & & \\
\hline $5^{\prime \prime}$ & 78.24 & 66.62 & 65.62 & & & \\
\hline $6^{\prime \prime}$ & 63.48 & & & & & \\
\hline
\end{tabular}

The reference substance is kaempferol 3-O- $\beta$-D-glucose- $(2 \rightarrow 1) \beta$-D-xyloside; $13 \mathrm{C} \mathrm{NMR,} 125 \mathrm{MHz}$, solution CD3OD; ${ }^{1} \mathrm{H}$ NMR, $500 \mathrm{MHz}$, solution CD3OD 
Table 6 Antibacterial effect of $\mathrm{F} 2$ on common bacteria/mold $(\mu \mathrm{g} / \mathrm{ml})(X \pm \mathrm{SD}, n=3)$

\begin{tabular}{llrrrrr}
\hline Test sample & \multicolumn{7}{l}{ Test strain } & \multicolumn{1}{l}{} \\
\cline { 2 - 7 } & E. coli & \multicolumn{1}{c}{$S E$} & \multicolumn{1}{l}{ Bt } & \multicolumn{1}{l}{ S. aureus } & \multicolumn{1}{l}{ A. niger } & $R$. nigricans \\
\hline Kanamycin & $21.25 \pm 0.13$ & $62.5 \pm 0.21$ & $57.95 \pm 0.15$ & $45.5 \pm 0.23$ & $55 \pm 0.23$ & $50 \pm 0.15$ \\
F2 & $20.71 \pm 0.14$ & $31.25 \pm 0.22$ & $15.90 \pm 0.09$ & $35.82 \pm 0.17$ & $47.43 \pm 0.12$ & $150 \pm 0.24$ \\
\hline
\end{tabular}

\section{References}

1. Ma L, Liu G, Zhang H, Liu X (2019) Understanding the difference of 4-hydroxyhexenal and 4-hydroxynonenal formation in various vegetable oils during thermal processes by kinetic and thermodynamic study. Int J Food Sci Tech 54(7):2468-2477

2. Ma L, Liu G, Liu X (2019) Amounts of malondialdehyde do not accurately represent the real oxidative level of all vegetable oils: a kinetic study of malondialdehyde formation. Int J Food Sci Technol 54(2):412-423

3. Chou TY, Lu YF, Inbaraj BS, Chen BH (2018) Camelia oil and Soybean-Camelia oil blend enhance antioxidant activity and cardiovascular protection in hamsters. Nutrition 51-52:86-94

4. Liu Y, Li Z, Xu H, Han Y (2016) Extraction of saponin from Camellia oleifera Abel cake by a combination method of alkali solution and acid isolation. J Chem NY 2016:1-8

5. Liau BC, Ponnusamy VK, Lee MR, Jong TT, Chen JH (2017) Development of pressurized hot water extraction for five flavonoid glycosides from defatted Camellia oleifera seeds (byproducts). Ind Crop Prod 95:296-304

6. Guo N, Tong T, Ren N, Tu Y, Li B (2018) Saponins from seeds of Genus Camellia: phytochemistry and bioactivity. Phytochemistry 149:42-55

7. Feng J, Ma YL, Sun P, Thakur K, Wang SY, Zhang JG, Wei ZJ (2020) Purification and characterization of $\alpha$-glucosidase inhibitory peptides from defatted camellia seed cake. Int J Food Sci Technol. https://doi.org/10.1111/ijfs.14613

8. Ye Y, Guo Y, Wang YF (2012) Free radical scavenging activity and anti-inflammatory property of the saponin from seeds of Camellia oleifera abel. Adv Mater Res 550-553:1262-1265

9. Zong J, Wang R, Bao G, Ling T, Zhang L, Zhang X, Hou R (2015) Novel triterpenoid saponins from residual seed cake of Camellia oleifera abel. Show anti-proliferative activity against tumor cells. Fitoterapia 104:7-13

10. Zong J, Wang D, Jiao W, Zhang L, Bao G, Ho CT, Wan X (2016) Oleifera saponin C6 from the seeds of Camellia oleifera abel: a novel compound inhibits proliferation through inducing cell-cycle arrest and apoptosis on human cancer cell lines in vitro. RSC Adv 6(94):91386-91393

11. Zong JF, Peng YR, Bao GH, Hou RY, Wan XC (2016) Two new oleanane-type saponins with anti-proliferative activity from Camellia oleifera abel. Seed Cake. Molecules 21(2):188

12. Imran M, Rauf A, Shah ZA, Saeed F, Imran A, Arshad MU, Mubarak MS (2019) Chemo-preventive and therapeutic effect of the dietary flavonoid kaempferol: a comprehensive review. Phytother Res 33(2):263-275

13. Matsuda H, Nakamura S, Morikawa T, Muraoka O, Yoshikawa M (2016) New biofunctional effects of the flower buds of Camellia sinensis and its bioactive acylated oleanane-type triterpene oligoglycosides. J Nat Med Tokyo 70(4):689-701

14. Yang JL, Ha TK, Dhodary B, Pyo E, Nguyen NH, Cho H, Oh WK (2015) Oleanane triterpenes from the flowers of Camellia japonica inhibit porcine epidemic diarrhea virus (PEDV) replication. J Med Chem 58(3):1268-1280

15. Xiao J (2017) Dietary flavonoid aglycones and their glycosides: which show better biological significance? Crit Rev Food Sci 57(9):1874-1905
16. Gentile D, Fornai M, Pellegrini C, Colucci R, Blandizzi C, Antonioli L (2018) Dietary flavonoids as a potential intervention to improve redox balance in obesity and related co-morbidities: a review. Nutr Res Rev 31(2):239-247

17. Perez Vizcaino F, Fraga CG (2018) Research trends in flavonoids and health. Arch Biochem Biophys 646:107-112

18. Wang D, Huo R, Cui C, Gao Q, Zong J, Wang Y, Hou R (2019) Anticancer activity and mechanism of total saponins from the residual seed cake of Camellia oleifera abel. In hepatoma-22 tumor-bearing mice. Food Funct 10(5):2480-2490

19. Cui C, Zong J, Sun Y, Zhang L, Ho CT, Wan X, Hou R (2018) Triterpenoid saponins from the genus Camellia: structures, biological activities, and molecular simulation for structure-activity relationship. Food Funct 9(6):3069-3091

20. Jiang S, Liu Q, Xie Y, Zeng H, Zhang L, Jiang X, Chen X (2015) Separation of five flavonoids from tartary buckwheat (Fagopyrum tataricum (L.) Gaertn) grains via off-line two dimensional highspeed counter-current chromatography. Food Chem 186:153-159

21. Gao Q, Ma R, Chen L, Shi S, Cai P, Zhang S, Xiang H (2017) Antioxidant profiling of vine tea (Ampelopsis grossedentata): offline coupling heart-cutting HSCCC with HPLC-DAD-QTOF-MS/ MS. Food Chem 225:55-61

22. Liang N, Cai P, Wu D, Pan Y, Curtis JM, Ganzle MG (2017) Highspeed counter-current chromatography (HSCCC) purification of antifungal hydroxy unsaturated fatty acids from plant-seed oil and Lactobacillus cultures. J Agric Food Chem 65(51):11229-11236

23. Li J, Wang H, Li J, Liu Y, Ding H (2020) LC-MS analysis of Myrica rubra extract and its hypotensive effects via the inhibition of GLUT 1 and activation of the NO/Akt/eNOS signaling pathway. RSC Adv 10(9):5371-5384

24. Zhang Y, Gu D, He S, Meng J, Wang JF, Wang YX, Wang Y, Tian J, Yang Y (2020) Enzyme reaction-guided identification of active components from the flowers of Sophora japonica var. violacea. Food Funct. https://doi.org/10.1039/D0FO00625D

25. Yoshikawa M, Morikawa T, Li N, Nagatomo A, Li X, Matsuda H (2005) Bioactive saponins and glycosides. XXIII. 1) Triterpene saponins with gastroprotective effect from the seeds of Camellia sinensis-Theasaponins E3, E4, E5, E6, and E7-. Chem Pharm Bull 53(12):1559-1564

26. Liu X, Painter RE, Enesa K, Holmes D, Whyte G, Garlisi CG, Smith CA (2016) High-throughput screening of antibiotic-resistant bacteria in picodroplets. Lab Chip 16(9):1636-1643

27. Wang SQ (2005) Perforation method for determining the titer of antibiotics. Biol Bull 40(3):2

28. Prakash G, Boopathy M, Selvam R, Johnsanthosh Kumar S, Subramanian K (2018) The effect of anthracene-based chalcone derivatives in the resazurin dye reduction assay mechanisms for the investigation of Gram-positive and Gram-negative bacterial and fungal infection. New J Chem 42(2):1037-1045

29. Ma T, Zhang QL, Ding CX, Suo YR, Ding CX, Wang HL (2014) Application of $\mathrm{pH}$-zone refined countercurrent chromatography in separation of alkaloids. Chin J Mod Appl Pharm 31(12):1539-1544

30. Zheng L, Chen L, Li J, Liang L, Fan Y, Qiu L, Deng Z (2019) Two kaempferol glycosides separated from Camellia oleifera meal by high-speed countercurrent chromatography and their possible application for antioxidation. J Food Sci 84(10):2805-2811 
31. Sticher O (2008) Natural product isolation. Nat Prod Rep 25(3):517-554

32. Li J, Chase HA (2010) Development of adsorptive (non-ionic) macroporous resins and their uses in the purification of pharmacologically-active natural products from plant sources. Nat Prod Rep 27(10):1493-1510

33. Qi LW, Wang CZ, Yuan CS (2011) Isolation and analysis of ginseng: advances and challenges. Nat Prod Rep 28(3):467-495

34. González M, González V (2010) Sample preparation of tropical and subtropical fruit biowastes to determine antioxidant phytochemicals. Anal Methods-UK 2(12): 1842

35. Sereshti H, Poursorkh Z, Aliakbarzadeh G, Zarre S, Ataolahi S (2018) An image analysis of TLC patterns for quality control of saffron based on soil salinity effect: a strategy for data (pre)-processing. Food Chem 239:831-839

36. Du LC, Wu BL, Chen JM (2008) Flavonoid triglycosides from the seeds of Camellia oleifera abel. Chin Chem Lett 19(11):1315-1318

37. Kataoka M, Hirata K, Kunikata T et al (2001) Antibacterial action oftryptanthrin and kaempferol, isolated from the indigo plant (Polygonum inctorium Lour.), against Helicobacter pylori-infected Mongolian gerbils. J Gastroenterol 36(1):5-9

38. Otsuka N, Liu MH, Shiota S et al (2008) Anti-methicillin resistant Staphylococcus aureus (MRSA) compounds isolated from Launus nobilis. Biol Pharm Bull 31(9):1794-1797

39. Brunskole M, Zorko K, Kerbler V et al (2009) Trihydroxynaphthalenereductase of Curvularia lunata - a target for flavonoid action? Chem Biol Interact 178(1-3):259-267
40. Kuete V, Nguemeving JR, Beng VP, Azebaze AGB, Etoa F-X, Meyer M, Nkengfack AE (2007) Antimicrobial activity of the methanolic extracts and compounds from Vismia laurentii De Wild (Guttiferae). J Ethnopharmacol 109(3):372-379

41. Saleem M, Nazir M, Ali MS, Hussain H, Lee YS, Riaz N, Jabbar A (2010) Antimicrobial natural products: an update on future antibioticdrug candidates. Nat Prod Rep 27(2):238-254

42. Sato Y, Suzaki S, Nishikawa T, Kihara M, Shibata H, Higuti T (2000) Phytochemical flavones isolated from Scutellaria barbata and antibacterial activity against methicillin-resistant Staphylococcus aureus. J Ethnopharmacol 72(3):483-488

43. Abdel Ghani SB, Weaver L, Zidan ZH, Ali HM, Keevil CW, Brown RCD (2008) Microwave-assisted synthesis and antimicrobial activities of flavonoid derivatives. Bioorg Med Chem Lett 18(2):518-522

44. Tsuchiya H, Sato M, Miyazaki T, Fujiwara S, Tanigaki S, Ohyama M, Iinuma M (1996) Comparative study on the antibacterial activity of phytochemical flavanones against methicillin-resistant Staphylococcus aureus. J Ethnopharmacol 50(1):27-34

45. Frija LMT, Ntungwe E, Sitarek P, Andrade JM, Toma M, Sliwinski T, Pombeiro AJL (2019) In vitro assessment of antimicrobial, antioxidant, and cytotoxic properties of saccharin-tetrazolyl and -thiadiazolyl derivatives: the simple dependence of the $\mathrm{pH}$ value on antimicrobial activity. Pharm (Basel) 12:167

Publisher's Note Springer Nature remains neutral with regard to jurisdictional claims in published maps and institutional affiliations. 